УДК 33.65

Маммадова Айан Урфан къъзы, докторант, Академия государственного управления

при Президенте Азербайджанской Республики, Азербайджан, г. Баку

ORCID ID: 0000-0002-9335-3491

DOI: $10.32702 / 2306-6814.2020 .1 .79$

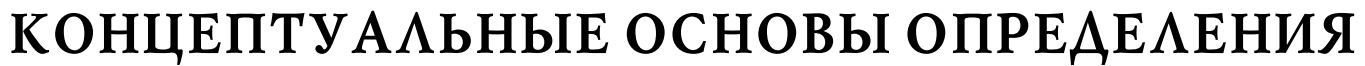 СТРАТЕГИИ УПРАВ АЕНИЯ ПРЕАПРИЯТИЙ В СОВРЕМЕННЫЙ ПЕРИОА
}

\author{
Mammadova Ayan Urfan gizi, \\ PhD student of the Academy of Public, dministration under the President of Azerbaijan Republic, Azerbaijan, Baku
}

\section{CONCEPTUAL BASES OF DETERMINING THE COMPANY'S MANAGEMENT STRATEGIES IN THE MODERN PERIOD}

\author{
Маммадова Аян Урфан кизи, \\ докторант, Академія Аержавного Управління \\ при Президентові Азербайджанської Республіки, Азербайджан, м. Баку
}

\section{КОНЦЕПТУААЬНІ ОСНОВИ ВИЗНАЧЕННЯ СТРАТЕГІЇ УПРАВАІННЯ ПІАПРИЕМСТВ В СУЧАСНИЙ ПЕРІОА}

Целью статьи является определение концептуальных основ стратегических изменений, их механизма и общих принципов в современных условиях на предприятиях обрабатывающей промышленности.

В процессе исследования были использованы методы статистического анализа, сравнения динамики роста активов предприятия и прогнозирования дальнейшего развития предприятий.

Новизна данной статьи заключается в том, что на основе анализа научных исследований автор попытался обосновать пути кардинального изменения процесса управления предприятиями. Наряду с этим для успешного осуществления стратегических изменений на этих предприятиях, а также с целью наибольшей и эффективной рентабельности был проведён анализ в различных направлениях.

В статье также отмечается, что изменения, происходящие в сфере управления, предусматривают новые формы коллективного управления предприятиями. Подчеркивая роль этих изменений, автор утверждает, что в процессе деятельности предприятия очень важно нормализация психологической среды в коллективе. Во многом рентабельность в деятельности предприятий является результатом благоприятной психологической среды. Отмечается, что в этом плане, проведенные правительством реформ в институциональных направлениях, высоко оценивается руководством в организации управления, повышении коллективного лидерства.

Также автор уделяет особое внимание психологическим аспектам управления, тем самым анализируя основы для предлагаемой стратегической реформы.

В заключении, принимая во внимание экономическую сторону стратегических изменений с точки зрения рентабельности, автор предлагает разработанный им трехмерный план стратегических изменений, координирующих все источники дохода, формирующий своевременную схему ценообразования для экономического изменения предприятия с учетом всех экономических показателей. Таким образом, на основе этого плана прогнозной оценки системы управления стратегическими изменениями на предприятиях обрабатывающей промышленности автор пришел к следующим выводам:

- определение пространственной среды с целью разработки коэффициентов и показателей внутренней системы предприятий пищевой промышленности свидетельствуют о некотором сужении данной среды;

- уровень удовлетворения потребности внутреннего рынка за 2014-2019 гг. по предприятиям пищевой промышленности незначительно уменьшился; 
- несколько улучшилось положение предприятий обрабатывающей промышленности во внешнеторговых операциях;

- существенно повысился уровень корпоративно-социальной ответственности в сфере повышения заработной платы персонала в предприятиях.

The purpose of this article is to consider strategic changes in enterprises, their mechanism and general principles in modern conditions.

In the research process, statistical analysis methods, a method for comparing the growth dynamics of enterprise assets, and methods for predicting the further development of enterprises were used.

The novelty of this article is that the author, on the basis of analysis of various studies of previous periods, tried to justify the ways of radically changing the process of enterprise management and in order to make strategic changes at these enterprises successful and in order to achieve the most and most effective profitability, an analysis was carried out in various directions.

The article also notes that the changes taking place in the management sphere provide for new forms of collective management of enterprises. Emphasizing the role of these changes, the author claims that in the process of the enterprise's activity, it is very important to normalize the psychological environment in the team. In many respects, profitability in enterprises is the result of a favorable psychological environment. It is noted that in this regard, the government's reforms in institutional areas are highly appreciated by management in organizing management and enhancing collective leadership.

The author also pays special attention to the psychological aspects of management, thereby analyzing the foundations for the proposed strategic reform.

In conclusion, taking into account the economic side of strategic changes in terms of profitability, the author proposes a three-dimensional plan of strategic changes developed by him that coordinates all sources of income, forming a timely pricing scheme for the economic change of an enterprise, taking into account all economic indicators. Thus, on the basis of this plan for the forecast assessment of the strategic change management system in manufacturing enterprises, the author came to the following rezults:

- the definition of the spatial environment in order to develop coefficients and indicators of the internal system of food industry enterprises showed a certain narrowing of this environment;

- the level of satisfaction of the needs of the domestic market for 2014-2019. for food industry enterprises will decrease slightly decreased;

- The position of manufacturing enterprises in foreign trade operations has somewhat improved;

- significantly increased the level of corporate social responsibility in the field of increasing the wages of personnel in enterprises. Keywords: formal methods, extrapolation of trends, econometric methods return on sales, the average export estimate

Метою статті є визначення концептуальних засад стратегічних змін, їх механізму та загальних принципів у сучасних умовах на підприємствах обробної промисловості.

У процесі дослідження було використано методи статистичного аналізу, метод порівняння динаміки зростання активів підприємства, методи прогнозування подальшого розвитку підприємств.

Новизна статті полягає в тому, що на основі аналізу наукових досліджень автор спробував обгрунтувати шляхи кардинальної зміни процесу управління підприємствами. Водночас для успішного здійснення стратегічних змін на цих підприємствах, а також з метою найбільшої і ефективної рентабельності було проведено аналіз у різних напрямах.

У статті також зазначається, що зміни, які відбуваються в сфері управління, передбачають нові форми колективного управління підприємствами. Підкреслюючи роль цих змін, автор стверджує, що в процесі діяльності підприємства дуже важлива нормалізація психологічного середовища в колективі. Багато в чому рентабельність удіяльності підприємств є результатом сприятливого психологічного середовища. Відзначається, що в цьому плані, проведених урядом реформ в інституційних напрямах, високо оцінюється керівництвом в організації управління, підвищенні колективного лідерства.

Також автор приділяє особливу увагу психологічним аспектам управління, тим самим аналізуючи основи для пропонованої стратегічної реформи.

У висновку, беручи до уваги економічну сторону стратегічних змін з точки зору рентабельності, автор пропонує розроблений ним тривимірний план стратегічних змін, які координують всі джерела доходу, що формує своєчасну схему ціноутворення для економічної зміни підприємства з урахуванням всіх економічних показників. Таким чином, на основі цього плану прогнозної оцінки на підприємствах обробної промисловості автордійшов до таких висновків:

- визначення просторового середовища з метою розробки коефіціентів і показників внутрішньої системи підприємств харчової промисловості показали про деяке звуження даного середовища;

- рівень задоволення потреби внутрішнього ринку за 2014-2019 рр. на підприємствах харчової промисловості незначно зменшився; 
- дещо поліпшилось положення підприємств обробної промисловості в зовнішньоторговельних операціях;

- істотно підвищився рівень корпоративно-соціальної відповідальності в сфері підвищення заробітної плати персоналу на підприємствах.

КлючеВые слова: формализоВанные методы, экстраполяция трендољ, эконометрические методы, рентабельность продаж, средняяэкспортная оченка.

Key words: formalized methods, trend extrapolation, econometric methods, sales profitability, average export estimate.

КлючоВі слова: формалізоВані методи, екстраполячія трендів, економетричніметоди, рентабельність продажіВ, середня експортна оцінка.

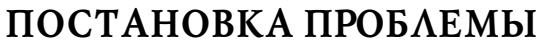

К перспективным методам прогнозирования системы управления стратегическими изменениями можно отнести методы моделирования, которые являются наиболее эфффективными в процессе прогнозирования предприятий стратегического направления. Их эффрективность заключается в том, что прогнозная оценка базируется на предварительном глубоком исследовании предприятий с выделением характерных особенностей и направленности с учетом основных достоинств и недостатков.

Значимое место в прогнозных оценках системы управления стратегическими изменениями на предприятиях обрабатывающей промышленности занимают логические и математические методы. В частности, к логическим методам прогнозирования можно отнести сценарный подход и методы организационного моделирования процессов.

\section{МЕТОАЫ И МЕТОАОАОГИЯ ИССАЕАОВАНИЯ}

В процессе исследования были использованы математические, фрормализованные методы, методы сравнения динамики роста активов предприятия, прогнозирования дальнейшего развития предприятий.

К математическим методам прогнозирования стратегическими изменениями можно отнести трендовые модели (или временная модель, т.е. весь процесс прогнозирования основывается на стратегических показателях, в зависимости от времени); эконометрические модели (стратегические изменения учитывают не только временную направленность, но и других влияющих факторов); имитационные модели (используются в кризисных и рисковых ситуациях с учетом случайных величин и перемен) [15, стр.288].

Формализованные методы подразделяются на: методы прогнозной экстраполяции (обычная экстраполяция, метод скользящих средних, метод экспоненциального сглаживания, экстраполяция трендов, авторегрессионные модели); целостно-структурные методы и модели (диагностический анализ, системный анализ, матричный метод, регрессионные модели, эконометрические методы, функционально-иерархическое моделирование, сетевое планирование); ассоциативные методы (имитационное моделирование, историко-логический анализ); метод опережающей информации (анализ исследований, оценка значимости изобретений, анализ патентной инфрормации) [12, стр. 28].

По нашему мнению, при прогнозных оценках системы управления стратегическими изменениями на уров- не предприятий следует использовать ряд принятых методов прогнозирования, которые поддаются практическим расчетам.

Данные методы основываются на предположениях, что предыдущая информация может способствовать предсказанию будущего. Эти методы включают [14, стр. 48]:

А. Метод предыдущего фактического значения принятие в случаи, когда не наблюдается существенных изменений временного ряда. Прогнозная оценка представляет собой последнее фактическое значение ряда, то есть это прогноз без изменения.

Однако, представленная модель не имеет большой точности, т.к. не защищена от случайных изменений, не включает трендовые показатели.

В. Метод простых средних величин - прогнозная оценка вычисляется на базе средних показателей временного ряда за предыдущие годы.

Представленные модели прогнозирования действуют на принципе, что в перспективе положение будет так же, как было в среднем за последний период. Данные модели устойчивы к неожиданным колебаниям, так как в них сглаживаются случайные величины по отношению к средним показателям.

Негативным моментом этого метода является усреднение ряда динамики по весьма длительному интервалу времени. Однако на практике значения временного ряда из недалекого прошлого лучше описывают прогноз, чем более старые значения этого же ряда. Отсюда можно воспользоваться методами скользящей средней [18, стр. 4].

С. Метод простой скользящей средней - прогнозная оценка вычисляется по последнему значению простой скользящей средней. Представленная модель включает только ближайшее прошлое на k-отсчетов по времени в глубину и базируется только на этих показателях.

D. Метод взвешенной скользящей средней - один из методов скользящей средней, которая базируется на гипотезах, что более ранние значения ряда соответственно отражают сложившийся тренд. В итоге, метод позволяет избежать задержку индикаторов, свойственных методу простой скользящей средней, то есть это очень активный метод [13, стр. 68].

В результате, каждому среднему показателю присваиваются удельный вес, который тем больший, чем более значимые показатели прибавляются. В сумме удельные веса равны 1. Прогнозное значение представляет собой последнее значение взвешенной скользящей средней.

Удельные веса вычисляются способом нормирования по единице или оцениваются методом экспертизы в 
Таблица 1.Определение основной стратегической цели предприятий обрабатывающей промышленности, млн манат

\begin{tabular}{|c|c|c|c|c|c|c|}
\hline $\begin{array}{l}\text { Наименование } \\
\text { предприятий } \\
\mathbf{Y}=\mathrm{V}_{1} / \mathrm{V}_{1}+\mathrm{V}_{2}\end{array}$ & \multicolumn{2}{|c|}{$\begin{array}{c}\text { Уровень удовлетворенности потребности } \\
\text { внутреннего рынка, (Y) }\end{array}$} & \multicolumn{2}{|c|}{$\begin{array}{c}\text { Объем продукции, } \\
\text { поставленной на } \\
\text { внутренний рынок, } \\
\left(\mathrm{V}_{1}\right)^{1} \\
\end{array}$} & \multicolumn{2}{|c|}{$\begin{array}{c}\text { Потенциальная } \\
\text { потребность } \\
\text { внутреннего рынка, } \\
\left(V_{2}\right)^{2} \\
\end{array}$} \\
\hline \multirow{2}{*}{$\begin{array}{l}\text { 1. Предприятия по } \\
\text { производству } \\
\text { пищевых продуктов }\end{array}$} & 2014 & 2019 (оценка) & 2014 & $\begin{array}{l}2019 \\
\text { (оценка) }\end{array}$ & 2014 & \begin{tabular}{|l}
2019 \\
(оценка)
\end{tabular} \\
\hline & $2596,7 / 2596+889,0=0,74$ & $3010,3 / 3010,3+1306,2=0,70$ & 2596,7 & 3010,3 & 889,0 & 1306,2 \\
\hline $\begin{array}{l}\text { 2. Предприятия } \\
\text { химической } \\
\text { промышленности } \\
\end{array}$ & $247,2 / 247,2+720,7=0,25$ & $565,5 / 565,5+1270,1=0,31$ & 247,2 & 565,5 & 720,7 & 1270,1 \\
\hline $\begin{array}{l}\text { 3. Предприятия по } \\
\text { производству строи- } \\
\text { тельных материалов }\end{array}$ & $500,3 / 500,3+176,2=0,74$ & $843,0 / 843,0+159,3=0,84$ & 500,3 & 843,0 & 176,2 & 159,3 \\
\hline & & & & & & \\
\hline
\end{tabular}

Примечание:

${ }^{1} \mathrm{~V}_{1}$ - по показателю обрабатывающей промышленности.

${ }^{2} \mathrm{~V}_{2}^{1}$ - по показателю импорта товаров.

${ }^{3}$ Среднегодовой тренд по показателю продукции обрабатывающей промышленности (пищевая, химическая и строительная) за 2010-2014 гг. составил 1,03; 1,18; 1,11, а тренд по показателю импорта $-1,08 ; 1,12 ; 0,98$.

порядке увеличения. Количество весов соответствует k-значению, т.е. степени их скольжения [17, стр. 288].

Приемы нормирования по единице включает определение количества последовательных показателей по порядку целых значении, определяемых степенью скольжения.

Е. Метод двойной скользящей средней.

Z. Метод экспоненциальной скользящей средней один из методов скользящей средней, который также включает присвоение наибольшего удельного веса последнему, наиболее значимому значению ряда, то есть это очень скоростной индикатор. В итоге, метод позволяет избежать задержку индикаторов, свойственных методу простой скользящей средней. Прогнозное значение равно последнему экспоненциальному скользящему среднему значению [14, стр. 48].

Основываясь на вышеперечисленные методы прогнозирования, нами были определены основные стратегические цели предприятий обрабатывающей промышленности на ближайшую перспективу (20152019 гг.), отраженные в таблице 1.

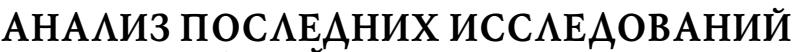 И ПУБАИКАЦИЙ}

Базовой основой исследования системы управления стратегическими изменениями является стратегический менеджмент, которому в последние годы посвящены многочисленные труды зарубежных ученых. И.Ансофрф в своей книге "Новая корпоративная стратегия" отмечает, что термин "стратегический менеджмент" включает в себя три основных компонента. Первый из них аналитическое фрормулирование корпоративной стратегии, развития управленческих способностей и управлению изменениями. Эту книгу автор посвятиль в основном к решению стратегических проблем [12].

Другой известный исследователь А.Андрейчикова в своей книге "Стратегический менеджмент в инновационных организациях" изложил концептуальные основы и анализ практики стратегического инновационного менеджмента в условиях глобальной конкуренции. Ос- новное внимание здесь уделено роли инноваций в условиях глобализации экономики, управлению знаниями как стратегическим ресурсом фрирмы, стратегии и организации НИОКР, учету неопределенностей в процессе НИОКР и при оценке инноваций, стратегической роли подготовки серийного производства на основе инноваций [2].

В книге Г. Болошина "Сравнительный менеджмент" отмечается, что стратегическое управление - это такое управление организацией, которое опирается на человеческий потенциал как основу организации, ориентирует производственную деятельность на запросы потребителей, осуществляет гибкое регулирование и своевременные изменения в организации, отвечающие вызову со стороны окружения и позволяющие добиваться конкурентных преимуществ, что в совокупности в результате позволяет организации выживать и достигать своей цели в долгосрочной перспективе [3].

В исследовании С. Богусловской "Системное стратегическое управление компанией: подходы и этапы постановки" автором систематизированы и представлены основные идеи, теории и модели; обобщен собственный опыт участия на различных этапах постановки и разработаны рекомендации по основным элементам системного стратегического управления. Существенное внимание уделено вопросам интеграции новых элементов и моделей с существующими системами управления предприятиями, включая формирование общего информационного поля и подготовку персонала к организационным изменениям [4].

Р. Грант в своей книге "Современный стратегический анализ" методично и последовательно рассказывает о понятии корпоративной стратегии, современном стратегическом менеджменте, глубоко разбирает природу и источники конкурентного преимущества компании, рассматривает бизнес-стратегии в контексте разных сфер деятельности, особые вопросы корпоративной стратегии [5].

Н. Лозик в своей книге "Стратегический менеджмент" раскрывает инструментарий стратегического ме- 
Таблица 2. Определение стратегической цели предприятий обрабатывающей промышленности на внешнем рынке и производственного персонала, млн манат

\begin{tabular}{|c|c|c|c|}
\hline \multirow[b]{2}{*}{$\begin{array}{c}\text { Наименование } \\
\text { предприятий }\end{array}$} & \multicolumn{3}{|c|}{ Средняя экспортная оценка (Рэкс) } \\
\hline & $\mathrm{P}_{\ni К С}=\mathrm{R}_{3} / \mathrm{V}_{\ni}$ & $\begin{array}{c}\text { Экспортная } \\
\text { выручка, }\left(R_{\ni}\right)^{5}, \\
\text { Тонн }\end{array}$ & $\begin{array}{c}\text { Объем экспортной } \\
\text { продукции, }\left(V_{э}\right)^{1}, \\
\text { млн манат }\end{array}$ \\
\hline \multirow{7}{*}{$\begin{array}{l}\text { 1. Предприятия по } \\
\text { производству } \\
\text { пищевых } \\
\text { продуктов }\end{array}$} & 2,05 & 648,2 & 316 \\
\hline & \multicolumn{3}{|c|}{ Рентабельность продаж $\left(\mathbf{R}_{\text {пр }}\right)$} \\
\hline & $\mathrm{R}_{\Pi \mathrm{P}}=\mathrm{P}_{\ni} / \mathrm{V}_{\text {пр }}$ & $\begin{array}{l}\text { Прибыль, } \\
\left(\text { Р }{ }^{3}, \text { млн манат }\right.\end{array}$ & $\begin{array}{l}\text { Выручка от продаж, } \\
\left(V_{\Pi P}\right)^{2}, \text { млн манат }\end{array}$ \\
\hline & 5,44 & 4840,3 & 889,0 \\
\hline & \multicolumn{3}{|c|}{ Производительность производственного персонала (П) } \\
\hline & $\mathbf{P}=\mathrm{V}_{0}+\mathrm{V}_{\mathrm{CP}}$, $\mathbf{\text { ысс. } \mathbf { ~ }}$ & $\begin{array}{l}\text { Объем продукции, } \\
\left(V_{0}\right)^{4}, \text { млн манат }\end{array}$ & $\begin{array}{l}\text { Численность персонала, } \\
\left.\text { (Ч }{ }_{\text {ср }}\right) \text {, тыс. чел. }\end{array}$ \\
\hline & 126,0 & 2596,7 & 20,6 \\
\hline
\end{tabular}

\begin{tabular}{|c|c|c|c|}
\hline \multirow{9}{*}{$\begin{array}{l}\text { 2. Предприятия } \\
\text { химической } \\
\text { промышленности }\end{array}$} & \multicolumn{3}{|c|}{ Средняя экспортная оценка (Рэкс) } \\
\hline & $\mathrm{P}_{\ni К \mathrm{C}}=\mathrm{R}_{3} / \mathrm{V}_{\ni}$ & $\begin{array}{l}\text { Экспортная } \\
\text { выручка, }\left(R_{\ni}\right)^{5}, \\
\text { Тонн }\end{array}$ & $\begin{array}{l}\text { Объем экспортной } \\
\text { продукции, }\left(V_{э}\right)^{1}, \\
\text { млн манат }\end{array}$ \\
\hline & 3,04 & 231,1 & 76,1 \\
\hline & \multicolumn{3}{|c|}{ Рентабельность продаж $\left(\mathbf{R}_{\text {пр }}\right)$} \\
\hline & $\mathrm{R}_{\Pi \mathrm{P}}=\mathrm{P}_{э} / \mathrm{V}_{\text {пр }}$ & $\begin{array}{l}\text { Прибыль, } \\
(\text { Р })^{3}, \text { млн манат }\end{array}$ & $\begin{array}{l}\text { Выручка от продаж, } \\
\left(V_{\text {пр }}\right)^{2} \text {, млн манат }\end{array}$ \\
\hline & 2,20 & 1584,1 & 720,7 \\
\hline & \multicolumn{3}{|c|}{ Производительность производственного персонала (П) } \\
\hline & $\mathbf{P}=\mathrm{V}_{0}+\mathrm{V}_{\mathrm{CP}}$, тыс. $\mathbf{~ м}$ & $\begin{array}{l}\text { Объем продукции } \\
\left(\mathrm{V}_{0}\right)^{4}, \text { млн манат }\end{array}$ & $\begin{array}{l}\text { Численность персонала, } \\
\text { (Ч }{ }_{\text {ср }} \text { ), тыс. чел. }\end{array}$ \\
\hline & 38,0 & 247,2 & 6,5 \\
\hline \multirow{9}{*}{$\begin{array}{l}\text { 3. Предприятия по } \\
\text { производству } \\
\text { строительных мате- } \\
\text { риалов }\end{array}$} & \multicolumn{3}{|c|}{ Средняя экспортная оценка (Рэкс) } \\
\hline & $\mathrm{P}_{\ni К \mathrm{C}}=\mathrm{R}_{3} / \mathrm{V}_{\ni}$ & $\begin{array}{l}\text { Экспортная } \\
\text { выручка, }\left(\mathbf{R}_{\jmath}\right)^{5}, \\
\text { тонн }\end{array}$ & $\begin{array}{l}\text { Объем экспортной } \\
\text { продукции, }\left(V_{э}\right)^{1}, \\
\text { млн манат }\end{array}$ \\
\hline & 2,9 & 9,0 & 3,1 \\
\hline & \multicolumn{3}{|c|}{ Рентабельность продаж $\left(\mathbf{R}_{\text {пр }}\right)$} \\
\hline & $\mathrm{R}_{\Pi \mathrm{P}}=\mathrm{P}_{\ni} / \mathrm{V}_{\text {пр }}$ & $\begin{array}{l}\text { Прибыль, } \\
(\text { Р })^{3}, \text { млн манат }\end{array}$ & $\begin{array}{l}\text { Выручка от продаж, } \\
\left(V_{\text {пр }}\right)^{2} \text {, млн манат }\end{array}$ \\
\hline & 4,49 & 792,1 & 176,2 \\
\hline & \multicolumn{3}{|c|}{ Производительность производственного персонала (П) } \\
\hline & $\mathbf{P}=\mathrm{V}_{0}+\mathrm{V}_{\mathrm{CP}}$, , тыс. $\mathbf{~ м}$ & $\begin{array}{l}\text { Объем продукции, } \\
\left(\mathrm{V}_{0}\right)^{4}, \text { млн манат }\end{array}$ & $\begin{array}{l}\text { Численность персонала, } \\
\text { (Ч ср), тыс. чел. }\end{array}$ \\
\hline & 37,9 & 500,3 & 13,2 \\
\hline
\end{tabular}

Примечание:

${ }^{1} \mathrm{~V}_{э}$ - по показателю экспорта продукции.

${ }^{2} \mathrm{~V}^{3}$ - по показателю импорта продукции.

${ }^{3} \mathrm{P}$ - по показателю розничного товара.

${ }^{4} \mathrm{~V}_{0}$ - по показателю обрабатывающей промышленности.

${ }^{5} \mathrm{R}_{э}$ - по показателю экспорта по стандартам международной квалификации. няет, как эфрфективно разрешить ситуации, связанные с созданием работоспособной команды, быть готовым к столкновению интересов, как увеличивать количество конструктивных предложений от сотрудников, как искоренять неуважение к чужому мнению и взаимное недоверие участников проводимого изменения [7].

А. Ажлуни и Е.А. Калинина обосновали выбор показателей для оценки эфффективности системы стратегического управления затратами промышленного предприятия, позволяющий не только оценить эфрфективность системы с позиции достижения цели (конкурентоспособность продукции), но и выявить направления стратегического воздействия на затраты, обеспечивающее повышение конкурентоспособности его продукции [8].

Л. Божко в своей работе "Требования к оценке эффеективности управления организационными изменениями" отмечает, что управление организационными изменениями на основе маркетингового подхода предполагает проведение маркетинговой оценки эфрфективности изменений. Такая оценка может проводиться на оперативном и стратегическом уровнях. Для стратегического уровня оценки предлагается использовать показатель стратегической эфффективности организационных изменений SEOC. В результате применения такого показателя оценка эфрфективности будет иметь комплексный характер, и учитывать особенности стратегического управления [9]

Монография Б. Райзберга и А. Тулякова посвящена всестороннему описанию состояния и проблем стратегического государственного и корпоративного планирования, управления объектами, процессами, отношениями в экономике и социальной сфере. Подвергнуты обстоятельному анализу сущность, содержание, признаки, фрормы стратегического, программно-целевого планирования, бюджетирования, используемые в России и в других странах. Изложены подходы к оценке качества, эффрективности, результативности государственных, федеральных целевых, региональных программ [10].

Книга известных американских ученых Хейзера Джей, Рендера Барри является фрундаментальным трудом, включающим в себя практически все варианты современных взглядов на совершенствование операционной деятельности компании. Охвачены все значимые проблем и в присущей ему основательной манере объяс- 
уровни обобщений, в первую очередь - стратегические. Книга содержит массу примеров использования всевозможных подходов в различных сочетаниях в компаниях из самых разных отраслей. Многие описанные решения годятся для применения в конкретных компаниях с незначительными коррективами [11] и др.

Как видно, исследованиям системы управления стратегическими изменениями уделено достаточное внимание ученых.

\section{ЦЕ $\Lambda \mathbf{b ~ С Т А Т Ь И ~}$}

Цель данной статьи заключается в рассмотрении стратегических изменений на предприятиях, их механизма и общих принципов в современных условиях.

\section{ИЗ АОЖЕНИЕ ОСНОВНОГО МАТЕРИААА ИССАЕАОВАНИЯ}

По нашим прогнозным оценкам по предприятиям пищевой промышленности, показатель уровня удовлетворенности потребности внутреннего рынка республики уменьшится с 0,74 в 2014 г. до 0,70 в 2019 г.; по предприятиям химической промышленности увеличится с 0,25 до 0,31; по предприятиям по производству строительных материалов - с 0,74 до 0,84.

Словом, в ближайшей перспективе предприятиям обрабатывающей промышленности предстоит решать серьезные стратегические задачи в сфере удовлетворения потребностей внутреннего рынка страны. С этой целью предприятиям обрабатывающей промышленности республики следует особое внимание уделять вопросам экспортно-импортного соотношения вырабатываемой продукции, глубоко исследовать показатели среднегодового тренда выпускаемой продукции и тем самым эффрективно управлять стратегическими изменениями [16, стр. 248].

Далее нами проведены расчеты по определению стратегической цели предприятий обрабатывающей промышленности во внешнеторговых операциях и производственного персонала (см. табл. 2). Было установлено, что средняя экспортная цена по предприятиям пищевой промышленности составил 2,05 млн манат, рентабельность продаж - 5,44\%, а производительность производственного персонала - 126,0 тыс. манат.

На предприятиях химической промышленности средняя экспортная цена установилась в объеме 3,4 млн манат, рентабельность - 3,04\%, а производительность - 38,0 тыс. манат.

И, наконец, по предприятиям по производству строительных материалов соответственно составили 2,9 млн манат, 4,49\% и 379 тыс. манат.

Полученные результаты показали, что при определении стратегической цели предприятий обрабатывающей промышленности на внешнем рынке следует активно использовать показатели экспорта и импорта товаров, розничного товарооборота по данной группе товаров, а также показатели экспорта по стандартам международной квалификации. Все это должно сопровождаться показателем производительности труда персонала предприятий обрабатывающей промышленности [19, стр. 448].

В завершении были определены стратегические цели предприятий обрабатывающей промышленности по показателю эффективности повышения уровня кор-
Таблица 3. Определение стратегической цели предприятий обрабатывающей промышленности по показателю эффективности повышения уровня корпоративно-социальной ответственности (за 2015-2019 гг.)

\begin{tabular}{|c|c|c|c|c|c|}
\hline \multirow{2}{*}{$\begin{array}{c}\text { Наименование } \\
\text { предприятий }\end{array}$} & \multicolumn{5}{|c|}{$\begin{array}{c}\text { Средний уровень заработной } \\
\text { платы, манат (факт) }\end{array}$} \\
\hline & 2010 & 2011 & 2012 & 2013 & 2014 \\
\hline \multirow{5}{*}{$\begin{array}{l}\text { 1. Предприятия по } \\
\text { производству } \\
\text { пищевых продуктов }\end{array}$} & 224,0 & 224,5 & 229,8 & 280,0 & 337,2 \\
\hline & \multicolumn{5}{|c|}{ Tрендовые показатели $^{1}$} \\
\hline & 1,0 & 1,002 & 1,024 & 1,218 & 1,204 \\
\hline & \multicolumn{5}{|c|}{ Прогнозная оценка, \% } \\
\hline & 367,5 & 400,6 & 436,6 & 475,9 & 518,7 \\
\hline \multirow{5}{*}{$\begin{array}{l}\text { 2. Предприятия } \\
\text { химической } \\
\text { промышленности }\end{array}$} & 351,4 & 357,0 & 453,3 & 460,4 & 489,1 \\
\hline & \multicolumn{5}{|c|}{ Tрендовые показатели ${ }^{2}$} \\
\hline & 1,0 & 1,016 & 1,27 & 1,016 & 1,062 \\
\hline & \multicolumn{5}{|c|}{ Прогнозная оценка, \% } \\
\hline & 533,4 & 570,7 & 610,4 & 653,1 & 698,8 \\
\hline \multirow{5}{*}{$\begin{array}{l}\text { 3. Предприятия по } \\
\text { производству строи- } \\
\text { тельных материалов }\end{array}$} & 407,7 & 408,9 & 481,8 & 525,1 & 563,8 \\
\hline & \multicolumn{5}{|c|}{ Tрендовые показатели $^{3}$} \\
\hline & 1,0 & 1,003 & 1,178 & 1,09 & 1,074 \\
\hline & \multicolumn{5}{|c|}{ Прогнозная оценка, \% } \\
\hline & 603,3 & 645,5 & 690,7 & 739,0 & 790,7 \\
\hline
\end{tabular}

Примечание:

${ }^{1}$ Среднегодовой трендовый показатель за 2010-2014 гг. составил - 1,09.

${ }^{2}$ Среднегодовой трендовый показатель за 2010-2014 гг. составил - 1,07.

${ }^{3}$ Среднегодовой трендовый показатель за 2010-2014 гг. составил - 1,07.

поративно-социальной ответственности, базовой основой который нами были выбраны доходы персонала в плане заработной платы (см. табл. 3).

Прогнозные оценки на период с 2015 по 2019 гг. показали, что заработная плата персонала предприятий обрабатывающей промышленности будет увеличиваться. В частности по предприятиям пищевой промышленности среднемесячная заработная плата персонала возрастает с 367,5 манат до 518,7 манат; по предприятиям химической промышленности - с 533,4 манат до 698,8 манат; по предприятиям по производству строительных материалов - с 603,3 манат до 790,7 манат.

Для дальнейшего повышения уровня эффрективности корпоративно-социальной ответственности руководителям предприятий обрабатывающей промышленности следует постоянно регулировать среднегодовые трендовые показатели по заработной плате и по другим доходным источникам персонала [16, стр. 48].

\section{ВЫВОАЫ}

Таким образом, прогнозная оценка системы управления стратегическими изменениями на предприятиях обрабатывающей промышленности позволил сделать ряд выводов:

- определение пространственной среды с целью разработки коэфффициентов и показателей внутренней системы предприятий пищевой промышленности показали о некотором сужении данной среды с 77,13\% до $64,4 \%$; предприятия химической промышленности - с $15,33 \%$ до $17,52 \%$; предприятия по производству строительных материалов - с 13,35\% до 12,23\%;

- уровень удовлетворения потребности внутреннего рынка за 2014-2019 гг. по предприятиям пищевой промышленности уменьшится - с 0,74 до 0,70; по 
предприятиям химической промышленности увеличится - с 0,25 до 0,31; по предприятиям по производству строительных материалов - с 0,74 до 0,84;

- несколько улучшится положение предприятий обрабатывающей промышленности во внешнеторговых операциях: средняя экспортная цена по предприятиям пищевой промышленности составил 2,05 млн манат, рентабельность продаж - 5,44\%, производительность персонала - 126,0 тыс. манат. Аналогичное положение наблюдается и по другим предприятиям;

- существенно повысится уровень корпоративносоциальной ответственности в сфере повышения заработной платы персонала в предприятиях.

\section{Литература:}

1. Ансоффр И. Новая корпоративная стратегия / Пер. с англ. - СПб.: Питер. 1999, - 416 с.

2. Андрейченков А. Стратегический менеджмент в инновационных организациях. - М.: ИНФРА-М. 2016. 396 c.

3. Болошин Г. Сравнительный менеджмент. - Ростов н/Д.: РГУ. 2001.

4. Богусловская С. Системное стратегическое управление компанией: подходы и этапы постановки. - СПб. Политехн. у-т, 2011. - 170 с.

5. Грант Р. Современный стратегический анализ. Пер. с англ. - СПб.: Питер. 2008, 560 с.

6. Лозик Н. Стратегический менеджмент. - М.: КНОРУС. 2015, - 152 с.

7. И.Адизес. Управляя изменениями / Пер. с англ. СПб.: Питер, 2008. - 224 с.

8. Ажлуни А.М., Калинина Е.А. Критерии оценки эфрфективности системы стратегического управления затратами / / Инвест Регион. - № 4. - 2009.

9. Божко Л. Требования к оценке эфрфективности управления организационными изменениями. - Тверь: ТГУ. 2013. /www.cyberleninka.ru /

10. Райзберг Б.А., Туляков А.В. Стратегическое планирование и управление социально-экономическими объектами. - М.: Экономика, 2016. - 223 с.

11. Хейзера Джей, Рендера Барри. Операционный менеджмент. В формате. Series: "Классика MBA". Publisher: СПб. Питер 2015, Edition: 10-е изд. Description: 1056 с. ил.

12. Рубчинский А.А. Методы и модели принятия управленческих решений. - М.: ЮРАЙТ, 2016. - 526 с.

13. Родионова В.Н. Стратегический менеджмент. М.: ИНФРА-М, 2016. - 80 с.

14. Романюк А.В. Макроэкономическое планирование и прогнозирование. - Тверь: ТГУ, 2014. - 75 с.

15. Черненко В.А., Шведова Н.Ю. Антикризисное управление. - М.: ЮРАЙТ, 2016. - 409 с.

16. Шапиро С.А. Организационное поведение. - М.: KНОРУС, 2015. - 344 c.

17. Шепеленко Г.И. Антикризисное управление производством и персоналом. - Ростов н/Д.: Феникс, 2015. - 237 с.

18. Щепакин М.Б. Управление качеством. - Ростов н/Д.: Феникс, 2014. - 256 с.

19. Юрьева Л.В. Управленческий учет на промышленных предприятиях в условиях инновационной экономики. - М.: КНОРУС, 2016. - 296 с.

\section{References:}

1.Ansoff, I. (1999), Novaya korporativnaya strategiya [New corporate strategy], Piter, St.Petersburg, Russia.

2. Andreichenkov, A. (2016), Strategicheskiy menedzhment $v$ innovatsionnykh organizatsiyakh [Strategic management in innovative organizations], INFRA-M, Moscow, Russia.

3. Boloshin, G. (2001), Sravnitel'nyy menedzhment [Comparative management], RGU, Rostov n/D, Russia.

4. Boguslovskaya, S. (2011), Sistemnoye strategicheskoye upravleniye kompaniyey: podkhody i etapy postanovki [Systemic strategic management of the company: approaches and stages of setting], SPb. Politekhn. U-t., St.Petersburg, Russia.

5. Grant, R. (2008), Sovremennyy strategicheskiy analiz [Modern strategic analysis.], Piter, St.Petersburg, Russia.

6. Lozik, N. (2015), Strategicheskiy menedzhment [Strategic management], KNORUS, Moscow, Russia.

7. Adizes, I. (2008), Upravlyaya izmeneniyami [Managing change], Piter, St.Petersburg, Russia.

8. Azhluni, A.M. Kalinina, Y.A. (2009), "Criteria for evaluating the effectiveness of the strategic cost management system", Invest Region, vol. 4.

9. Bozhko, L. (2013), Trebovaniya k otsenke effektivnosti upravleniya organizatsionnymi izmeneniyami [Requirements for evaluating the effectiveness of managing organizational changes], TGU, Tver', St.Petersburg, Russia.

10. Rayzberg, B.A. and Tulyakov, A.V. (2016), Strategicheskoye planirovaniye i upravleniye sotsial'noekonomicheskimi ob"yektami [Strategic planning and management of socio-economic facilities], Ekonomika, Moscow, Russia.

11. Hazer, J. and Render, B. (2015), Operatsionnyy menedzhment [Operational management], Piter, St.Petersburg, Russia.

12. Rubchinskiy, A.A. (2016), Metody i modeli prinyatiya upravlencheskikh resheniy [Methods and models of managerial decision making], YURAYT, Moscow, Russia.

13. Rodionova, V.N. (2016), Strategicheskiy menedzhment [Strategic management], INFRA-M, Moscow, Russia.

14. Romanyuk, A.V. (2014), Makroekonomicheskoye planirovaniye i prognozirovaniye [Macroeconomic planning and forecasting], TGU, Tver, Russia.

15. hernenko, V.A. and Shvedova, N.Y. (2016), Antikrizisnoye upravleniye [Anticrisis management], YURAYT, Moscow, Russia.

16. Shapiro, S.A. (2015), Organizatsionnoye povedeniye [Organizational behavior], KNORUS, Moscow, Russia.

17. Shepelenko, G.I. (2015), Antikrizisnoye upravleniye proizvodstvom i personalom [Crisis management of production and personnel], Feniks, Rostov n/D, Russia.

18. Shchepakin, M.B. (2014), Upravleniye kachestvom [Management control], Feniks, Rostov n /D, Russia.

19. Yur'yeva, L.V. (2016), Upravlencheskiy uchet na promyshlennykh predpriyatiyakh v usloviyakh innovatsionnoy ekonomiki [Management accounting at industrial enterprises in an innovative economy], KNORUS, Moscow, Russia. Cтаття надійшла до редакцї 29.12.2019 p. 